
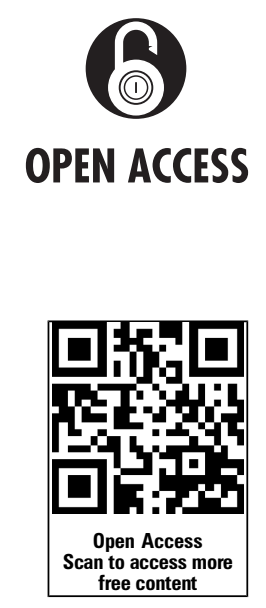

Handling editor Tore K Kvien

- Additional material is published online only. To view please visit the journal online (http://dx.doi.org/10.1136/ annrheumdis-2014-205351)

For numbered affiliations see end of article.

\section{Correspondence to} Dr Hermine I Brunner, Cincinnati Children's Hospital Medical Center, Division of Rheumatology and the Anderson Center for Excellence in Health Care, PRCSG Coordinating Center, MC 4010, 3333 Burnet Avenue, Cincinnati, $\mathrm{OH} 45229$ 3930, USA;

Hermine.brunner@cchmc.org

HIB and NR contributed equally.

Received 4 February 2014 Revised 10 April 2014 Accepted 16 April 2014 Published Online First 16 May 2014

To cite: Brunner $\mathrm{HI}$, Ruperto N, Zuber Z, et al. Ann Rheum Dis 2015;74: 1110-1117.

\title{
Efficacy and safety of tocilizumab in patients with polyarticular-course juvenile idiopathic arthritis: results from a phase 3 , randomised, double-blind withdrawal trial
}

Hermine I Brunner, ${ }^{1}$ Nicolino Ruperto, ${ }^{2}$ Zbigniew Zuber, ${ }^{3}$ Caroline Keane, ${ }^{4}$ Olivier Harari, ${ }^{4}$ Andrew Kenwright, ${ }^{4}$ Peng Lu, ${ }^{5}$ Ruben Cuttica, ${ }^{6}$ Vladimir Keltsev, ${ }^{7}$ Ricardo M Xavier, ${ }^{8}$ Inmaculada Calvo, ${ }^{9}$ Irina Nikishina, ${ }^{10}$ Nadina Rubio-Pérez, ${ }^{11}$ Ekaterina Alexeeva, ${ }^{12}$ Vyacheslav Chasnyk, ${ }^{13}$ Gerd Horneff, ${ }^{14}$ Violetta Opoka-Winiarska, ${ }^{15}$ Pierre Quartier, ${ }^{16}$ Clovis A Silva, ${ }^{17}$ Earl Silverman, ${ }^{18}$ Alberto Spindler, ${ }^{19}$ Eileen Baildam, ${ }^{20} \mathrm{M}$ Luz Gámir, ${ }^{21}$ Alan Martin, ${ }^{22}$ Christoph Rietschel, ${ }^{23}$ Daniel Siri, ${ }^{24}$ Elzbieta Smolewska, ${ }^{25}$ Daniel Lovell, ${ }^{1}$ Alberto Martini, ${ }^{2,26}$ Fabrizio De Benedetti, ${ }^{27}$ for the Paediatric Rheumatology International Trials Organisation (PRINTO) and the Pediatric Rheumatology Collaborative Study Group (PRCSG)

\section{ABSTRACT}

Objective To evaluate the interleukin-6 receptor inhibitor tocilizumab for the treatment of patients with polyarticular-course juvenile idiopathic arthritis (pcJIA).

Methods This three-part, randomised, placebocontrolled, double-blind withdrawal study (NCT00988221) included patients who had active pcIIA for $\geq 6$ months and inadequate responses to methotrexate. During part 1, patients received open-label tocilizumab every 4 weeks ( 8 or $10 \mathrm{mg} / \mathrm{kg}$ for body weight (BW) $<30 \mathrm{~kg} ; 8 \mathrm{mg} / \mathrm{kg}$ for $\mathrm{BW} \geq 30 \mathrm{~kg}$ ). At week 16, patients with $\geq$ JAA-American College of

Rheumatology (ACR) 30 improvement entered the 24week, double-blind part 2 after randomisation 1:1 to placebo or tocilizumab (stratified by methotrexate and steroid background therapy) for evaluation of the primary end point: JIA flare, compared with week 16. Patients flaring or completing part 2 received open-label tocilizumab.

Results In part 1, 188 patients received tocilizumab ( $<30 \mathrm{~kg}: 10 \mathrm{mg} / \mathrm{kg}(\mathrm{n}=35)$ or $8 \mathrm{mg} / \mathrm{kg}(\mathrm{n}=34) ; \geq 30 \mathrm{~kg}$ : $\mathrm{n}=119$ ). In part 2, 163 patients received tocilizumab $(n=82)$ or placebo $(n=81)$. JIA flare occurred in $48.1 \%$ of patients on placebo versus $25.6 \%$ continuing tocilizumab (difference in means adjusted for stratification: $-0.21 ; 95 \% \mathrm{Cl}-0.35$ to -0.08 ; $p=0.0024$ ). At the end of part $2,64.6 \%$ and $45.1 \%$ of patients receiving tocilizumab had JIA-ACR70 and JIAACR90 responses, respectively. Rates/100 patient-years (PY) of adverse events (AEs) and serious AEs (SAEs) were 480 and 12.5 , respectively; infections were the most common SAE (4.9/100 PY).

Conclusions Tocilizumab treatment results in significant improvement, maintained over time, of pcJIA signs and symptoms and has a safety profile consistent with that for adults with rheumatoid arthritis. Trial registration number: NCT00988221.

\section{INTRODUCTION}

Juvenile idiopathic arthritis (JIA) is a heterogeneous group of chronic arthritides of unknown cause with an onset before 16 years of patient age. ${ }^{1}$ A substantial proportion of patients have polyarticular-course JIA (pcJIA) and are at risk for profound disability. ${ }^{2}$ Although these patients may respond to methotrexate (MTX) or biological agents approved for pcJIA, up to $30 \%$ continue to have active disease. ${ }^{45}$

Interleukin-6 (IL-6) is increased in the serum and synovial fluid of patients with pcJIA; IL-6 concentrations are positively correlated with the severity of joint involvement and with C-reactive protein (CRP) levels. ${ }^{6}$ Tocilizumab is a humanised, monoclonal, antihuman IL-6 receptor (IL-6R) antibody that binds to membrane and soluble IL-6R, inhibiting IL-6-mediated signalling. ${ }^{7}$ Clinical trials have shown that tocilizumab is efficacious in the treatment of patients with rheumatoid arthritis (RA) and systemic JIA (sJIA). ${ }^{9} 10$

The aim of this study was to evaluate the efficacy and safety of tocilizumab in patients with active pcJIA and inadequate responses to MTX.

\section{METHODS}

\section{Study design}

This three-part study, CHERISH, was conducted by members of the Paediatric Rheumatology International Trials Organisation (PRINTO) ${ }^{11}$ and the Pediatric Rheumatology Collaborative Study Group (PRCSG) at 58 centres in Australia, Canada, Europe, Latin America, Russia and the USA.

Part 1 was a 16 -week, active-treatment, openlabel, lead-in period in which patients whose body weight $(\mathrm{BW})$ was $30 \mathrm{~kg}$ or more received intravenous tocilizumab $8 \mathrm{mg} / \mathrm{kg}(8 \mathrm{mg} / \mathrm{kg}$ for $30 \mathrm{~kg}$ or more group) every 4 weeks. Patients weighing less 
than $30 \mathrm{~kg}$ were randomly assigned 1:1 to receive intravenous tocilizumab at $8 \mathrm{mg} / \mathrm{kg}(8 \mathrm{mg} / \mathrm{kg}$ for less than $30 \mathrm{~kg}$ group) or $10 \mathrm{mg} / \mathrm{kg}(10 \mathrm{mg} / \mathrm{kg}$ for less than $30 \mathrm{~kg}$ group) every 4 weeks. Based on pharmacokinetic modelling and simulation, doses of $10 \mathrm{mg} / \mathrm{kg}$ for patients weighing less than $30 \mathrm{~kg}$ achieved tocilizumab exposure comparable to that of $8 \mathrm{mg} / \mathrm{kg}$ for patients weighing $30 \mathrm{~kg}$ or more.

At week 16, patients entered the double-blind withdrawal period (part 2) provided they had experienced at least a JIA-American College of Rheumatology (ACR) 30 response (JIA-ACR30), defined as $30 \%$ or greater improvement of three or more of the six JIA core response variables (JIA-CRVs) without greater than $30 \%$ worsening in more than one of the remaining JIA-CRVs compared with baseline ${ }^{12}$ (see 'Assessment and outcomes'). Patients who did not achieve JIA-ACR30 response in part 1 were withdrawn from the study.

In part 2, JIA-ACR30 responders were randomly assigned 1:1 to receive placebo or to continue tocilizumab as in part 1 , stratified by MTX and glucocorticoid use. Patients continued in part 2 until week 40, unless they experienced JIA-flare $(30 \%$ or greater worsening in three of the six JIA-CRVs without more than $30 \%$ improvement in more than one remaining JIA-CRV) compared with week $16 .{ }^{13}$ On completion of part 2 or after JIA-flare, patients entered part 3 of the study ( 64 weeks) and received open-label tocilizumab at the same dose received in part 1. Throughout, patients continued treatment until withdrawal of informed consent, loss of follow-up or study end.

Here, we report efficacy results to week 40 (end of part 2) and safety results to the last data cut (184.4 patient-years (PY) of tocilizumab exposure). The study was conducted in accordance with the Declaration of Helsinki and good clinical practice guidelines and with local requirements. Enrolment started 14 October 2009 and ended 31 January 2011. The study was reported following recommendations of the CONSORT statement. $^{14}$

\section{Patients}

Eligible patients were 2 to 17 years old, received diagnoses of rheumatoid factor-positive or rheumatoid factor-negative pcJIA or extended oligoarticular JIA, ${ }^{15}$ had disease durations of at least 6 months and had inadequate responses to or were intolerant of MTX. Patients also had to have five or more active joints, defined as the presence of swollen joints (or, in the absence of swelling, joints with limitation of movement (LOM) plus pain on motion and/or tenderness with palpation), with LOM present in at least three of the active joints. Patients could have been previously treated with biological agents. Stable doses of non-steroidal anti-inflammatory drugs, low-dose glucocorticoids (no greater than $0.2 \mathrm{mg} / \mathrm{kg} /$ day prednisone; daily maximum, $10 \mathrm{mg}$ ) and MTX (10-20 mg/m $\mathrm{m}^{2}$ body surface area/week) were allowed. Additional eligibility criteria are listed in online supplementary appendix S1.

\section{Assessment and outcomes}

Clinical assessments (baseline, week 2, week 4 and every 4 weeks thereafter) included the six JIA-CRVs: number of joints with active arthritis, number of joints with LOM, physician global assessment (PGA) of disease activity (range, 0-100; $0=$ inactive disease), assessment of patient overall well-being (range, $0-100 ; 0=$ very poor), physical function measured by the Childhood Health Assessment Questionnaire-Disability Index (CHAQ-DI; range, $0-3 ; 0=$ no disability) and erythrocyte sedimentation rate (ESR). ${ }^{16}$ Clinically inactive disease was defined as PGA, indicating no disease activity plus absence of all the following: joints with active arthritis, uveitis and ESR greater than $20 \mathrm{~mm} / \mathrm{h}^{17}$

The primary efficacy end point was the proportion of patients in whom a JIA-flare occurred ${ }^{13}$ during part 2 (up to and including week 40) compared with week 16 . Secondary end points evaluated at week 40 included JIA-ACR30/50/70/90 responses, ${ }^{16}$ change from baseline in JIA-CRVs and clinically inactive disease. ${ }^{17}$

\section{Statistical analysis}

Sample size estimation assumed JIA-flare rates of 35\% for the tocilizumab groups and $65 \%$ for the placebo group in part 2 . Thus, 60 patients had to be randomly assigned to each group in part 2 to achieve more than $80 \%$ power to detect a significant difference in JIA-flare rates between groups using a two-sided significance test with $\alpha=0.05$. Based on an expected JIA-ACR30 response rate of $65 \%$ in the tocilizumab group in part 1 , recruitment of 185 patients into part 1 was planned to ensure that a sufficient number of patients were available for randomisation in part 2. To control for the type 1 error rate, secondary end points were tested in a hierarchical fixed-sequence approach provided the primary end point was found to be statistically significant (see online supplementary table S1).

Primary end point analysis was conducted with the CochranMantel-Haenszel (CMH) test, adjusted for stratification factors (background use of MTX and oral glucocorticoids); patients who withdrew or for whom the end point could not be determined were considered to have experienced JIA-flare. For secondary end points, the $\mathrm{CMH}$ test was used to determine statistical significance for differences in JIA-ACR30/50/70/90 responders at week 40 compared with baseline; patients who escaped or withdrew or for whom the end point could not be determined were considered non-responders. Continuous variables were evaluated using analysis of variance, adjusted for baseline differences between groups and stratification variables. A last-observation-carried-forward approach was used for patients who withdrew or experienced flare and who escaped to open-label tocilizumab.

Ad hoc analysis was conducted in patients continuously treated with tocilizumab up to week 40 , including those who escaped from blinded to open-label tocilizumab, using an intent-to-treat (ITT) approach. Evaluations of JIA-flare (primary outcome), JIA-ACR response rates and clinically inactive disease status were performed in real time by independent masked evaluators at the coordinating centres of PRINTO and PRCSG, according to validated criteria. ${ }^{2} 131617$

The safety population consisted of all patients who received at least one dose of study medication. Safety data included fullexposure data for each patient. Exposure to tocilizumab varied for individual patients, depending on the period from the first dose of tocilizumab to the date of data cut or withdrawal (maximum exposure, 1.8 years). Serious infections were defined in accordance with the definition of serious adverse events (SAEs) in the International Conference on Harmonisation guidelines. ${ }^{18}$ The trial is registered with ClinicalTrials.gov, number NCT00988221.

\section{RESULTS}

\section{Patient demographics and disposition}

In part 1, 188 patients were enrolled and received at least one dose of tocilizumab (figure 1). Disease characteristics at baseline were generally similar across the three groups, with exceptions as expected according to the body weight-based dosing regimen (table 1). 




Figure 1 Summary of patient disposition. Part 1 treatment is indicated in parentheses. ${ }^{2}$ Three patients were not included in the ITT population for part 2 because they discontinued before receiving a single dose of study drug. $A E$, adverse event; BW, body weight; JIA-ACR, juvenile idiopathic arthritis-American College of Rheumatology; ITT, intent-to-treat.

Table 1 Demographic and disease characteristics at baseline

\begin{tabular}{|c|c|c|c|c|}
\hline & $\begin{array}{l}\text { Tocilizumab } \\
8 \mathrm{mg} / \mathrm{kg}<30 \mathrm{~kg} \\
\mathrm{n}=34\end{array}$ & $\begin{array}{l}\text { Tocilizumab } \\
10 \mathrm{mg} / \mathrm{kg}<30 \mathrm{~kg} \\
\mathrm{n}=35\end{array}$ & $\begin{array}{l}\text { Tocilizumab } \\
8 \mathrm{mg} / \mathrm{kg} \geq 30 \mathrm{~kg} \\
\mathrm{n}=119\end{array}$ & $\begin{array}{l}\text { All } \\
\text { Tocilizumab } \\
\mathrm{N}=188^{*}\end{array}$ \\
\hline Age (years) & $7.6(2.71)$ & $6.9(3.02)$ & $13.1(2.78)$ & $11.0(4.01)$ \\
\hline Females, n (\%) & $24(71)$ & $30(86)$ & 90 (76) & $144(77)$ \\
\hline Weight $(\mathrm{kg})$ & $22.4(5.3)$ & $20.7(5.7)$ & $50.0(12.6)$ & $39.6(17.3)$ \\
\hline Disease duration (years) & $3.5(2.57)$ & $3.4(2.39)$ & $4.7(4.16)$ & $4.2(3.67)$ \\
\hline Rheumatoid factor positive, $\mathrm{n}(\%)$ & $2(6)$ & $4(11)$ & $48(40)$ & $54(29)$ \\
\hline Previous DMARD use, $\mathrm{n}(\%)$ & $26(76)$ & $21(60)$ & $87(73)$ & $134(71)$ \\
\hline Previous biological agent use, $\mathrm{n}(\%) \dagger$ & $6(18)$ & $8(23)$ & $47(39)$ & $61(32)$ \\
\hline Joints with active arthritis, $n$ & $21.2(13.6)$ & $23.9(18.3)$ & $18.9(13.0)$ & $20.3(14.3)$ \\
\hline Joints with LOM, n & $17.3(13.3)$ & $23.1(19.2)$ & $16.0(12.7)$ & $17.6(14.4)$ \\
\hline Assessment of patient overall well-being VAS & $59.1(26.2)$ & $51.5(26.9)$ & $51.6(24.1)$ & $52.9(25.0)$ \\
\hline Physician global assessment of JIA activity VAS & $64.7(18.5)$ & $64.7(20.5)$ & $59.4(21.3)$ & $61.4(20.7)$ \\
\hline $\mathrm{CRP}(\mathrm{mg} / \mathrm{L}) \ddagger$ & $26.6(33.6)$ & $21.8(32.3)$ & $22.8(38.8)$ & $23.3(36.6)$ \\
\hline CHAQ-DI score & $1.8(0.68)$ & $1.7(0.71)$ & $1.2(0.69)$ & $1.4(0.74)$ \\
\hline ESR $(\mathrm{mm} / \mathrm{h}) \S$ & $36.6(23.0)$ & $35.1(24.1)$ & $34.2(26.7)$ & $34.8(25.5)$ \\
\hline Concurrent MTX use, n (\%) & $30(88)$ & $29(83)$ & $89(75)$ & $148(79)$ \\
\hline Dose $\left(\mathrm{mg} / \mathrm{m}^{2} /\right.$ week $)$ & $13.8(2.9)$ & $16.5(11.1)$ & $11.6(2.7)$ & $13.0(5.7)$ \\
\hline Concurrent glucocorticoid use, $n(\%) q$ & $18(53)$ & $15(43)$ & $54(45)$ & $87(46)$ \\
\hline Dose (mg/kg/day)ף & $0.15(0.038)$ & $0.15(0.033)$ & $0.12(0.052)$ & $0.13(0.048)$ \\
\hline
\end{tabular}

Values are mean (SD) unless stated otherwise.

*Included are all patients randomly assigned to receive tocilizumab $10 \mathrm{mg} / \mathrm{kg}$ (patients weighing $<30 \mathrm{~kg}$ ), tocilizumab $8 \mathrm{mg} / \mathrm{kg}$ (patients weighing $<30 \mathrm{~kg}$ ) or tocilizumab $8 \mathrm{mg} / \mathrm{kg}$ (patients weighing $\geq 30 \mathrm{~kg}$ ) in part 1 .

tNine per cent of patients previously received three or more biological agents. TNF inhibitors were administered to 56 patients, anakinra to 5 patients, abatacept to 5 patients and canakinumab to 1 patient.

¥Standard reference range was $0-10 \mathrm{mg} / \mathrm{L}$.

$\S$ Standard reference range was $0-18 \mathrm{~mm} / \mathrm{h}$

IThese were measured in prednisone equivalents.

CHAQ-DI, Childhood Health Assessment Questionnaire-Disability Index; CRP, C-reactive protein; DMARD, disease-modifying antirheumatic drug; ESR, erythrocyte sedimentation rate; JIA, juvenile idiopathic arthritis; LOM, limitation of movement; MTX, methotrexate; TNF, tumour necrosis factor; VAS, visual analogue scale (range, 0-100 mm). 
In part $1,15(7.9 \%)$ of 188 patients did not achieve JIA-ACR30 response and were discontinued from the study (figure 1). Additional withdrawals in part 1 occurred because of AEs (three patients), refusal of treatment (three patients) and loss of follow-up (one patient). Of the remaining 166 patients who entered part 2, 6 were discontinued (AEs, 3 patients; insufficient therapeutic response, 2 patients; withdrawal of consent, 1 patient). Because 3 of the 166 patients entering part 2 discontinued the study before receiving a single dose of study drug, the ITT population for part 2 was 163 patients-81 randomly assigned to placebo and 82 to continued tocilizumab.

\section{Efficacy in the open-label phase (part 1)}

Part 1 was completed by 168 (89.4\%) of 188 patients achieving JIA-ACR30 response (figure 2A). Higher-level JIA-ACR70 and JIA-ACR90 responses were attained by 117 (62.2\%) of 188 and $49(26.1 \%)$ of 188 patients, respectively. All six JIA-CRVs markedly improved from baseline to week 16 (figure $2 \mathrm{~B}$ ).

JIA-ACR30/50/70/90 response rates were numerically lower in the $8 \mathrm{mg} / \mathrm{kg}$ less than $30 \mathrm{~kg}$ group than in the other two groups (figure 2C). Consistently, tocilizumab concentrations over time and steady-state exposures were numerically lower in the $8 \mathrm{mg} / \mathrm{kg}$ less than $30 \mathrm{~kg}$ group than in the other two groups (see online supplementary table S2, supplementary figure S1A).

A

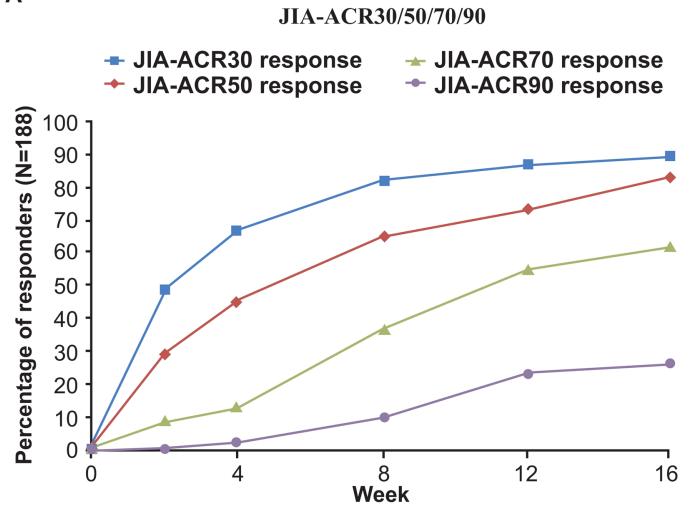

C

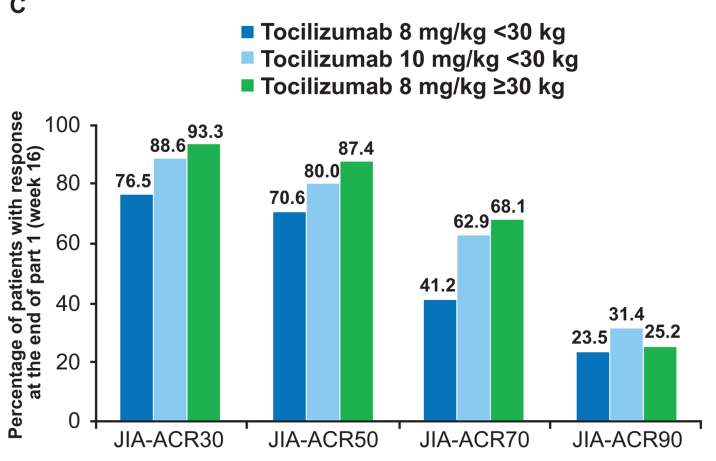

Changes in soluble IL-6R levels and inflammation markers (CRP, ESR) were also more similar between $10 \mathrm{mg} / \mathrm{kg}$ for the less than $30 \mathrm{~kg}$ group and $8 \mathrm{mg} / \mathrm{kg}$ for the $30 \mathrm{~kg}$ or more group (see online supplementary figure S1B-D).

\section{Efficacy in the double-blind, withdrawal phase (part 2)}

The primary end point at week 40 was met; there were significantly more JIA-flares in the placebo group than in patients remaining on tocilizumab $(39 / 81(48.1 \%)$ vs $21 / 82(25.6 \%)$; adjusted difference in flare rate: $-0.21 ; 95 \% \mathrm{CI}-0.35$ to -0.08 ; $\mathrm{p}=0.0024)$. JIA-flares were evident in the placebo group as early as 28 days after randomisation in part 2 (figure 2D). Robustness of the primary end point result was confirmed by logistic regression analysis (see online supplementary appendix S2).

In the placebo and the tocilizumab groups, JIA-ACR70 and JIA-ACR90 response rates were numerically higher in patients receiving MTX than in those not receiving MTX; rates were numerically lower in patients who previously received other biological agents than in biological-naive patients (table 2). No differences were observed in response to tocilizumab between patients who were rheumatoid factor-positive and those who were not (data not shown).

Ad hoc analysis of patients who received tocilizumab continuously in parts 1 and 2, including those who escaped in part 2,
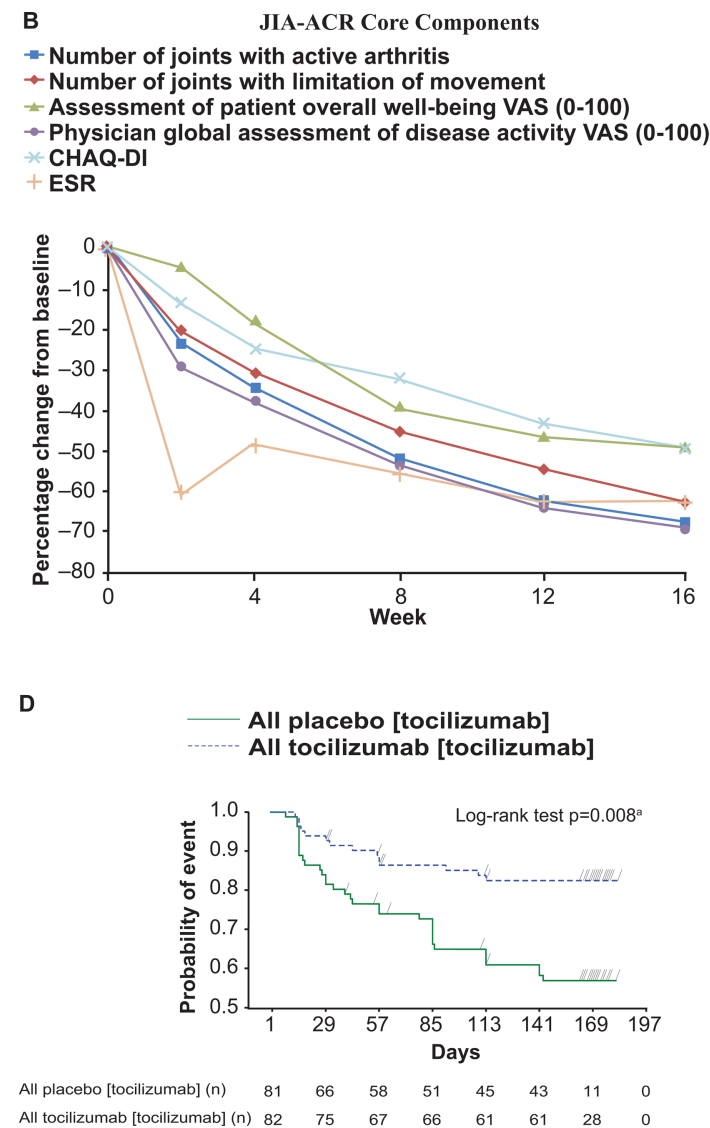

Figure 2 (A) JIA-ACR30/50/70/90 response rates by visit in part 1. (B) Line plot of JIA-ACR core components by week in part 1. (C) JIA-ACR30/50/ $70 / 90$ improvement by treatment group at the end of part 1 at week 16. (D) Time to JIA-ACR30 flare after randomisation in the withdrawal phase (part 2); part 1 treatment is indicated in parentheses. For JIA-ACR responses (A, C), $n=188$. For JIA-ACR core components (B), $n=182-187$ for number of joints with active arthritis and number of joints with limitation of movement; $n=178-184$ for assessment of patient overall well-being; $\mathrm{n}=181-187$ for physician global assessment of disease activity; $\mathrm{n}=182-184$ for CHAQ-DI; and $\mathrm{n}=182-188$ for ESR. For time to JIA-ACR30 flare (D),


was a predefined, exploratory analysis. HR, $0.36 ; 95 \% \mathrm{Cl} 0.19$ to 0.67 . CHAQ-DI, Childhood Health Assessment Questionnaire-Disability Index; ESR, erythrocyte sedimentation rate; JIA-ACR, juvenile idiopathic arthritis-American College of Rheumatology; VAS, visual analogue scale. 
Table 2 Proportion of patients in the ITT population with JIA-ACR70 and JIA-ACR90 response at week 40 by background methotrexate use, background glucocorticoid use and previous biological agent use at baseline*

\begin{tabular}{|c|c|c|c|c|c|}
\hline \multirow[b]{2}{*}{ Concomitant therapies and previous exposure to biological agent } & \multirow[b]{2}{*}{ Response level } & \multicolumn{2}{|l|}{$\begin{array}{l}\text { Placebo } \\
n=81 t\end{array}$} & \multicolumn{2}{|l|}{$\begin{array}{l}\text { Tocilizumab } \\
n=82 t\end{array}$} \\
\hline & & Yes & No & Yes & No \\
\hline Background methotrexate & $\begin{array}{l}\text { JIA-ACR70 } \\
\text { JIA-ACR90 }\end{array}$ & $\begin{array}{l}30 / 64(46.9) \\
18 / 64(28.1)\end{array}$ & $\begin{array}{l}4 / 17(23.5) \\
1 / 17(5.9)\end{array}$ & $\begin{array}{l}45 / 67(67.2) \\
32 / 67(47.8)\end{array}$ & $\begin{array}{l}8 / 15(53.3) \\
5 / 15(33.3)\end{array}$ \\
\hline Background glucocorticoid & $\begin{array}{l}\text { JIA-ACR70 } \\
\text { JIA-ACR90 }\end{array}$ & $\begin{array}{r}14 / 38(36.8) \\
5 / 38(13.2)\end{array}$ & $\begin{array}{l}20 / 43(46.5) \\
14 / 43(32.6)\end{array}$ & $\begin{array}{l}23 / 33(69.7) \\
16 / 33(48.5)\end{array}$ & $\begin{array}{l}30 / 49(61.2) \\
21 / 49(42.9)\end{array}$ \\
\hline Previous biological agent & $\begin{array}{l}\text { JIA-ACR70 } \\
\text { JIA-ACR90 }\end{array}$ & $\begin{array}{l}2 / 23(8.7) \\
2 / 23(8.7)\end{array}$ & $\begin{array}{l}32 / 58(55.2) \\
17 / 58(29.3)\end{array}$ & $\begin{array}{r}13 / 27(48.1) \\
5 / 27(18.5)\end{array}$ & $\begin{array}{l}40 / 55(72.7) \\
32 / 55(58.2)\end{array}$ \\
\hline
\end{tabular}

*Patients who withdrew or escaped to open-label tocilizumab or for whom the end point could not be determined were classified as non-responders.

tValues are $\mathrm{n}$ of $\mathrm{N}(\%$ of $\mathrm{N})$.

ITT, intent-to-treat; JIA-ACR, juvenile idiopathic arthritis-American College of Rheumatology based on percentage changes of the JIA-CRVs.

demonstrated JIA-ACR70 and JIA-ACR90 response rates of $78.0 \%(64 / 82)$ and $48.8 \%(40 / 82)$, respectively, at week 40 compared with baseline, with improvement from baseline in all individual JIA-CRVs (table 3).

\section{Safety}

AEs and SAEs are shown in table 4 for the safety population $(n=188)$ at the time of data cut. Overall, 159 (84.6\%) patients reported at least one AE. Rates of AEs/100 PY of exposure were similar across the three groups $(8 \mathrm{mg} / \mathrm{kg}$ for $30 \mathrm{~kg}$ or more, $501.9 ; 10 \mathrm{mg} / \mathrm{kg}$ for less than $30 \mathrm{~kg}, 445.6 ; 8 \mathrm{mg} / \mathrm{kg}$ for less than $30 \mathrm{~kg}, 471.9)$. A total of 16 AEs in 16 (8.5\%) patients were considered severe, and seven AEs led to study discontinuation. Common AEs were pneumonia, reported in four $(2.1 \%)$ patients (three in the $8 \mathrm{mg} / \mathrm{kg}$ for $30 \mathrm{~kg}$ or more group, one in the $10 \mathrm{mg} / \mathrm{kg}$ for less than $30 \mathrm{~kg}$ group), followed by bronchitis in two (1.1\%) patients (both in the $10 \mathrm{mg} / \mathrm{kg}$ for less than $30 \mathrm{~kg}$ group) and cellulitis in two (1.1\%) patients (both in the $8 \mathrm{mg} / \mathrm{kg}$ for $30 \mathrm{~kg}$ or more group).

No deaths were reported during the study, and no malignancies were identified. In the safety population, 17 (9.0\%) patients reported 22 SAEs, with a rate of 12.5/100 PY. Also, 5 of the 22 SAEs (benign intracranial hypertension, uveitis, urinary calculus, pneumonia, cellulitis) in $5(2.7 \%)$ patients were considered by the investigator to be related to tocilizumab.

Laboratory abnormalities included alanine aminotransferase elevations $3 \times$ upper limit of normal (ULN) or greater in seven $(3.7 \%)$ patients, aspartate aminotransferase elevations $3 \times$ ULN or greater in one $(0.5 \%)$ patient, neutropenia (less than 1000 cells $/ \mathrm{mm}^{3}$ ) in seven $(3.7 \%)$ patients and thrombocytopenia (less than 50000 cells $/ \mathrm{mm}^{3}$ ) in two $(1 \%)$ patients. These haematological abnormalities were not associated with infection or bleeding events. Low-density lipoprotein (LDL)-cholesterol levels $110 \mathrm{mg} / \mathrm{dL}$ or greater were observed in $21(11.4 \%)$ patients, whereas total cholesterol levels $170 \mathrm{mg} / \mathrm{dL}$ or greater occurred in 64 (34.6\%) of 185 patients assessed for cholesterol. No patients were treated with lipid-lowering agents. One patient had a positive antitocilizumab antibody assay result, without anaphylactic reaction, and discontinued during part 1 for lack of efficacy.

\section{DISCUSSION}

Results of this study demonstrate that intravenous tocilizumab $10 \mathrm{mg} / \mathrm{kg}$ administered every 4 weeks in patients weighing less than $30 \mathrm{~kg}$ and intravenous tocilizumab $8 \mathrm{mg} / \mathrm{kg}$ administered every 4 weeks in patients weighing $30 \mathrm{~kg}$ or more are safe and efficacious for the management of pcJIA. Results were clinically meaningful because a high proportion (89\%) of patients achieved JIA-ACR30 response by week 16;62\% of patients achieved JIA-ACR70 response, and $26 \%$ even achieved JIA-ACR90 response.

The primary end point at week 40 was met: significantly more placebo-treated than tocilizumab-treated patients experienced JIA-flare during the double-blind, 24-week withdrawal phase. Patients who received tocilizumab for 40 weeks experienced marked improvement in all JIA-CRVs from baseline.

At the end of part 1, JIA-ACR response rates in patients weighing less than $30 \mathrm{~kg}$ who received tocilizumab $10 \mathrm{mg} / \mathrm{kg}$

Table 3 Improvement of all JIA-ACR core components at the end of part 2 (week 40) for the ITT population receiving tocilizumab in parts 1 and $2(n=82)^{*}$ compared with baseline

\begin{tabular}{|c|c|c|c|}
\hline JIA-ACR core response variablest & Baseline & Week 40 & Week 40 (change from baseline) $\ddagger$ \\
\hline Joints with active arthritis (range, $0-71$ ) & $19.7(13.95)$ & $3.2(8.06)$ & $-14.5(11.14)$ \\
\hline Joints with a limitation of movement (range, $0-67$ ) & $16.5(13.81)$ & $3.9(6.95)$ & $-10.2(8.97)$ \\
\hline Assessment of patient overall well-being, VAS (range, $0-100$ ) & $45.5(23.11)$ & $8.8(16.12)$ & $-31.1(28.52)$ \\
\hline Physician global assessment of disease activity, VAS (range, $0-100$ ) & $57.8(20.30)$ & $6.2(7.75)$ & $-45.6(21.47)$ \\
\hline CHAQ-DI (range, $0-3$ ) & $1.216(0.67)$ & $0.333(0.47)$ & $-0.804(0.65)$ \\
\hline $\mathrm{ESR}(\mathrm{mm} / \mathrm{h})$ & $31.7(22.88)$ & $5.4(6.08)$ & $-25.2(21.97)$ \\
\hline
\end{tabular}

${ }^{*}$ Ad hoc analysis.

†Values are mean (SD).

¥Change from baseline was calculated using last-observation-carried-forward imputation for missing values; in other columns, missing values were not imputed.

CHAQ-DI, Childhood Health Assessment Questionnaire-Disability Index; ESR, erythrocyte sedimentation rate; ITT, intent-to-treat; JIA-ACR, juvenile idiopathic arthritis-American College of Rheumatology; ULN, upper limit of normal; VAS, visual analogue scale $(0-100 \mathrm{~mm})$. 
Table 4 Serious adverse events and adverse events occurring in at least $5 \%$ of the patients by treatment group for events

\begin{tabular}{|c|c|c|c|c|}
\hline \multirow[b]{2}{*}{ Adverse events* } & \multirow{2}{*}{$\begin{array}{l}\text { Part } 1 \dagger \\
\text { Tocilizumab } \\
\mathrm{N}=188\end{array}$} & \multicolumn{2}{|l|}{ Part $2 \ddagger$} & \multirow[b]{2}{*}{$\begin{array}{l}\text { All-exposure safety group§ } \\
\mathrm{N}=188\end{array}$} \\
\hline & & All tocilizumab $n=82$ & $\begin{array}{l}\text { All placeboł } \\
\mathrm{n}=81\end{array}$ & \\
\hline Duration in study (years) & 59.92 & 32.33 & 27.41 & 184.4 \\
\hline Patients with at least one $\mathrm{AE}$ & $124(66.0)$ & $58(70.7)$ & $60(74.1)$ & $159(84.6)$ \\
\hline Total number of AEs $q$ & 365 & 147 & 141 & 885 \\
\hline Rate of AEs per $100 \mathrm{PY}^{* *}$ & 609.2 & 454.7 & 514.4 & 479.8 \\
\hline \multicolumn{5}{|l|}{ Most frequently reported (>5\%) AEs } \\
\hline Nasopharyngitis & $23(12.2)$ & $14(17.1)$ & $9(11.1)$ & $39(20.7)$ \\
\hline Headache & $15(8.0)$ & $3(3.7)$ & - & $26(13.8)$ \\
\hline Upper respiratory infection & $13(6.9)$ & $4(4.9)$ & $2(2.5)$ & $19(10.1)$ \\
\hline Cough & $7(3.7)$ & $2(2.4)$ & $1(1.2)$ & $18(9.6)$ \\
\hline Pharyngitis & $8(4.3)$ & $3(3.7)$ & $3(3.7)$ & $17(9.0)$ \\
\hline Nausea & $12(6.4)$ & $2(2.4)$ & $2(2.5)$ & $16(8.5)$ \\
\hline Diarrhoea & $7(3.7)$ & $2(2.4)$ & $3(3.7)$ & $14(7.4)$ \\
\hline Rhinitis & $7(3.7)$ & $2(2.4)$ & $1(1.2)$ & $14(7.4)$ \\
\hline Vomiting & $4(2.1)$ & $3(3.7)$ & $1(1.2)$ & $14(7.4)$ \\
\hline Abdominal pain & $5(2.7)$ & $2(2.4)$ & $2(2.5)$ & $13(6.9)$ \\
\hline Oropharyngeal pain & $8(4.3)$ & $1(1.2)$ & $5(6.2)$ & $13(6.9)$ \\
\hline Rash & $3(1.6)$ & $4(4.9)$ & $1(1.2)$ & $10(5.3)$ \\
\hline \multicolumn{5}{|l|}{ SAES } \\
\hline Patients with at least one SAE & $7(3.7)$ & $3(3.7)$ & $3(3.7)$ & $17(9.0)$ \\
\hline Rate of SAEs per $100 \mathrm{PY}$ & 13.4 & 9.3 & 10.9 & 12.5 \\
\hline Patients with at least one infectious SAE & $4(2.1)$ & $1(1.2)$ & - & $9(4.8)$ \\
\hline Rates of infectious SAEs per $100 \mathrm{PY}$ & 6.7 & 3.1 & - & 4.9 \\
\hline SAEs by preferred term & & & - & \\
\hline Pneumonia & $1(0.5)$ & $1(1.2)$ & - & $4(2.1)$ \\
\hline Bronchitis & $2(1.1)$ & - & - & $2(1.1)$ \\
\hline Cellulitis & $1(0.5)$ & - & - & $2(1.1)$ \\
\hline Varicella & - & - & - & $1(0.5)$ \\
\hline Neck injury & - & - & - & $1(0.5)$ \\
\hline Synovial rupture & - & - & - & $1(0.5)$ \\
\hline Upper limb fracture & - & $1(1.2)$ & - & $1(0.5)$ \\
\hline Sclerosing cholangitis & $1(0.5)$ & - & - & $1(0.5)$ \\
\hline Hypertransaminasemia & $1(0.5)$ & - & - & $1(0.5)$ \\
\hline Back pain & - & - & - & $1(0.5)$ \\
\hline Osteoporosis & - & - & - & $1(0.5)$ \\
\hline Familial Mediterranean fevert† & - & - & - & $1(0.5)$ \\
\hline Uveitis & - & - & $1(1.2)$ & $1(0.5)$ \\
\hline Constipation & $1(0.5)$ & - & - & $1(0.5)$ \\
\hline Benign intracranial hypertension & $1(0.5)$ & - & - & $1(0.5)$ \\
\hline Psychosomatic disease & - & $1(1.2)$ & - & $1(0.5)$ \\
\hline Urinary calculus & - & - & - & $1(0.5)$ \\
\hline Enterocolitis & - & - & $1(1.2)$ & \\
\hline Complicated migraine & - & - & $1(1.2)$ & \\
\hline AEs leading to study drug discontinuation & - & & & \\
\hline Increased blood bilirubin level $\ddagger \ddagger$ & - & $1(1.2)$ & - & $1(0.5)$ \\
\hline Serum sickness-like reaction§§ & $1(0.5)$ & - & - & $1(0.5)$ \\
\hline Gastroenteritis & - & - & $1(1.2)$ & $1(0.5)^{\star * *}$ \\
\hline Pneumonia & $1(0.5)$ & - & - & $1(0.5)$ \\
\hline Sclerosing cholangitis $\uparrow \uparrow$ & $1(0.5)$ & - & - & $1(0.5)$ \\
\hline Benign intracranial hypertension & $1(0.5)$ & - & - & $1(0.5)$ \\
\hline
\end{tabular}

Values are $n(\%)$ unless stated otherwise.

* Multiple occurrences of the same AE in one individual were counted only once, except where noted.

tSixteen-week, open-label, lead-in part 1 with all patients receiving tocilizumab.

$\ddagger$ Both groups received tocilizumab open-label during part 1 before entering part 2 (24-week withdrawal phase). AE data on open-label tocilizumab escape therapy were excluded.

§Summarises all AEs except those that occurred in a patient once on placebo and includes data after week 40 because safety was based on the data cut.

IMultiple occurrences of the same AE in one individual were counted.

** Patient-year.

t†Recurrence in patient with pcJIA, with flare of familial Mediterranean fever.

$\ddagger \ddagger$ Highest total bilirubin reading, $50 \mu \mathrm{mol} / \mathrm{L}$ (normal range, $3-24 \mu \mathrm{mol} / \mathrm{L}$ ); two consecutive readings $>51 \mathrm{mmol} / \mathrm{L}$ mandated withdrawal per protocol. The event resolved without

sequelae.

$\S \S$ Patient with serum sickness-like reaction and subcutaneous swelling on dorsum of hand, forearm and foot; the patient was discontinued from the study.

9ीThe patient had transaminitis on study entry: $139 \mathrm{U} / \mathrm{L}$ aspartate aminotransferase, $147 \mathrm{U} / \mathrm{L}$ alanine aminotransferase; highest readings: $287 \mathrm{U} / \mathrm{L}$ aspartate aminotransferase, $289 \mathrm{U} / \mathrm{L}$ alanine aminotransferase. Liver biopsy was performed on study day 134; results were compatible with sclerosing cholangitis. The event was unresolved and considered unrelated to study medication.

$* * *$ Occurred 46 days after the last of five doses of placebo.

$A E$, adverse event; JIA, juvenile idiopathic arthritis; PY, patient-years; SAE, serious adverse event. 
were similar to those in patients weighing $30 \mathrm{~kg}$ or more who received tocilizumab $8 \mathrm{mg} / \mathrm{kg}$, whereas rates were lower in patients weighing less than $30 \mathrm{~kg}$ who received tocilizumab $8 \mathrm{mg} / \mathrm{kg}$. This is consistent with the $8 \mathrm{mg} / \mathrm{kg}$ dose resulting in a lower tocilizumab exposure in patients weighing less than $30 \mathrm{~kg}$. Higher body weight-adjusted dosing in lighter patients with pcJIA is consistent with the kind of dosing required to achieve comparable tocilizumab exposures and JIA-ACR response rates between lighter and heavier patients with pcJIA. ${ }^{10}$

Notably, the results reported here reflect the efficacy of tocilizumab when $24(14.7 \%)$ of 163 patients received suboptimal doses of tocilizumab (ie, patients weighing less than $30 \mathrm{~kg}$ who received the $8 \mathrm{mg} / \mathrm{kg}$ dose). The absolute difference in flare rates among groups observed in this study may be influenced by longevity of the drug response and duration of the withdrawal phase.

Biological agent-naive patients experienced a lower incidence of flare regardless of assignation to tocilizumab or placebo. This observation is in keeping with reports from clinical trials of other biological agents in pcJIA ${ }^{5}$ and is consistent with the notion that patients who received previous biological therapy represent a more treatment-resistant subgroup. ${ }^{19}$ Nevertheless, JIA-ACR70 response was observed in $48.1 \%$ of tocilizumabtreated patients whose previous treatment with a biological agent failed.

Similarly, concomitant MTX yielded fewer flare events, regardless of assignation to tocilizumab or placebo. Statistical testing was not planned to assess the significance of the impact of MTX on efficacy outcomes. However, even without background MTX, 53.3\% of the patients receiving tocilizumab achieved JIA-ACR70 response by week 40 .

The pattern of AEs observed in this study of patients with pcJIA is consistent with the known safety profile of tocilizumab reported in other phase 3 studies. $^{20}$ The frequency of neutropenia $(3.7 \%)$ was similar to that reported in adults with RA $(4.7 \%)^{20}$ but lower than that reported in children with sJIA $(16.9 \%)$ who receive tocilizumab in 2-weekly intervals. ${ }^{10}$ Similarly, the rate of serious infections (4.9/100 PY) was lower than that reported for children with sJIA $(11.0 / 100 \mathrm{PY})^{10}$ but similar to that reported for adults with RA (4.7/100 PY).

Hypercholesterolemia occurred in adults with $\mathrm{RA}^{20}$ and in children with sJIA. Levels of cholesterol exceeding the ULN for totalcholesterol or LDL-cholesterol were observed at least once in 31\% of the patients who received tocilizumab. ${ }^{10}$ Total-cholesterol levels above $170 \mathrm{mg} / \mathrm{dL}$ occurred in $34.6 \%$ of children in this study with pcJIA, whereas $11.4 \%$ had LDL-cholesterol levels of $110 \mathrm{mg} / \mathrm{dL}$ or greater. Total-cholesterol and LDL-cholesterol exceeding such levels have been considered marginally elevated in children. ${ }^{21}$ The clinical relevance of isolated elevations in cholesterol level, as observed in this study, is unclear because of diurnal variations in lipid levels and because of differences in normative values based on age and sex. ${ }^{22}$ Of note, lipid elevations in adults with RA treated with tocilizumab do not appear to convey increased risks for cardiovascular disorders or events with appropriate management. ${ }^{9}$

This study allowed for the acquisition of data on the magnitude of the therapeutic effect of tocilizumab in patients with active pcJIA (part 1) and for the demonstration that this effect was indeed due to tocilizumab (part 2). Although the withdrawal design of this study was valuable in minimising placebo treatment in children with pcJIA, it had potential limitations. Patients who did not achieve JIA-ACR30 responses in the openlabel, lead-in phase on tocilizumab were withdrawn, limiting information about dose responsiveness. Lead-in treatment of placebo patients with tocilizumab limited the ability to determine safety and efficacy differences over the limited withdrawal period, especially because the biological effects of tocilizumab might have endured beyond the time taken to clear the drug.

\section{Conclusions}

Tocilizumab treatment provided sustained and clinically meaningful improvement for patients with pcJIA on monthly dosing of $8 \mathrm{mg} / \mathrm{kg}$ in patients weighing $30 \mathrm{~kg}$ or more and $10 \mathrm{mg} / \mathrm{kg}$ in patients weighing less than $30 \mathrm{~kg}$. The safety profile of tocilizumab in this patient population was consistent with that seen in adults with RA.

\section{Author affiliations}

${ }^{1}$ Division of Rheumatology, Department of Pediatrics, University of Cincinnati, Cincinnati Children's Hospital Medical Center, PRCSG Coordinating Center,

Cincinnati, Ohio, USA

${ }^{2}$ Istituto Giannina Gaslini, Pediatria II, Reumatologia, PRINTO Coordinating Centre, Genoa, Italy

${ }^{3}$ Department of Pediatric Neurology and Rheumatology, St. Louis Children's Hospital, Cracow, Poland

${ }^{4}$ Roche Products Ltd, Welwyn Garden City, UK

${ }^{5}$ Roche, Nutley, New Jersey, USA

${ }^{6}$ Hospital General de Niños Pedro de Elizalde, Buenos Aires, Argentina

${ }^{7}$ Department of Pediatric Cardiology and Rheumatology, Samara Regional Clinical Hospital, Samara, Russia

${ }^{8}$ Rheumatology Service, Department of Internal Medicine, Hospital de Clínicas de

Porto Alegre, Universidade Federal do Rio Grande do Sul, Porto Alegre, Brazil

${ }^{9}$ Paediatric Rheumatology Department, Hospital Universitario La Fe, Valencia, Spain

${ }^{10}$ Pediatric Department, Federal State Budgetary Institution (Research Institute of

Rheumatology named after V.A. Nasonova) under the Russian Academy of Medical

Sciences, Moscow, Russia

${ }^{11}$ Department of Pediatrics, Hospital Universitario, Universidad Autónoma de Nuevo León, Nuevo León, Mexico

${ }^{12}$ Scientific Center, Children's Health of RAMS and IM Sechenov First Moscow State Medical University, Moscow, Russia

${ }^{13}$ St Petersburg State Pediatric Medical Academy, St Petersburg, Russia

${ }^{14}$ Asklepios Klinik Sankt Augustin, Centre for General Pediatrics and Neonatology,

Sankt Augustin, Germany

${ }^{15}$ Department of Pediatric Pulmonology and Rheumatology, Medical University of Lublin, Lublin, Poland

${ }^{16}$ Unité d'Immunologie, Hématologie et Rhumatologie Pediatrique, Université ParisDescartes, Hôpital Necker-Enfants Malades and Institut IMAGINE, Paris, France

${ }^{17}$ Pediatric Rheumatology Unit, Faculdade de Medicina da Universidade de São Paulo, Children's Institute, São Paulo, Brazil

${ }^{18}$ Department of Paediatrics, University of Toronto, Toronto, Ontario, Canada

${ }^{19}$ Department of Medicine, Universidad Nacional de Tucumán, Tucumán, Argentina

${ }^{20}$ Department of Paediatric Rheumatology, Alder Hey Children's Foundation NHS

Trust, Liverpool, UK

${ }^{21}$ Servicio de Reumatología, Hospital Universitario Ramón y Cajal, Madrid, Spain

${ }^{22}$ Tulsa Bone \& Joint Associates, Tulsa, Oklahoma, USA

${ }^{23} \mathrm{Clementine} \mathrm{Kinderhospital,} \mathrm{Verein} \mathrm{Frankfurter} \mathrm{Stiftungskrankenhäuser,} \mathrm{Frankfurt,}$ Germany

${ }^{24} \mathrm{CAICl}$ Institute, Rosario, Argentina

${ }^{25}$ Department of Pediatric Cardiology and Rheumatology, Medical University of Łódź, Łódź, Poland

${ }^{26}$ Dipartimento di Pediatria, Università di Genova, Genoa, Italy

${ }^{27}$ Ospedale Pediatrico Bambino Gesù, Rome, Italy

Acknowledgements We thank Sara Duggan, PhD, Mark English, PhD, Santo D'Angelo, PhD, MS, and Susan Quiñones, PhD, who provided writing and editorial services on behalf of $F$. Hoffmann-La Roche Ltd. We are indebted to the staff of the PRINTO and PRCSG coordinating centres, namely T. Sherrard, A. Johnson,

A. Merritt, W. Long, Simona Angioloni, Laura Carenini, Chiara Pallotti, Eugenia

Mosci, Marco Garrone, Irene Gregorini, Silvia Scala, Luca Villa and Giuseppe

Silvestri. We also thank all additional members of the PRINTO and PRCSG networks who participated as investigators (physicians, nurses and other health professionals) in the study and whose enthusiastic efforts made this work possible: Argentina: Graciela Espada, MD; Australia: Roger Allen, MD, Jeffrey Chaitow, MD; Belgium: Rik Joos, MD, Carine Wouters, MD; Brazil: Sheila Knupp, MD, Flavio Sztajnbok, MD; Canada: David Cabral, MD, Kristin Houghton, MD, Johannes Roth, MD, Heinrike Schmeling, MD; France: Chantal Job-Deslandre, MD, Christian Jorgensen, MD, Isabelle Konepaut, MD; Germany: Kirsten Minden, MD, Frank Weller, MD; Italy: Valeria Gerloni, MD, Francesco Zulian, MD; Mexico: Ruben Burgos-Vargas, MD, Carolina Duarte Salazar, MD, Eunice Solis Vallejo, MD; Peru: Armando Calvo, MD, 
José Chavez, MD, Manuel Ferrandiz Zavaler, MD; Poland: Anna Gruenpeter, MD, Katarzyna Kobusinska, MD; Russia: Alexey Sarychev, MD, Elena Zholobova, MD; UK: Athimalaipet Ramanan, MD, Patricia Woo, MD; USA: Abraham Gedalia, MD, Steven Goodman, MD, Yukiko Kimura, MD, Karen Onel, MD, and Kenneth Schikler, MD.

Collaborators Argentina: Graciela Espada; Australia: Roger Allen, Jeffrey Chaitow; Belgium: Rik Joos, Carine Wouters; Brazil: Sheila Knupp, Flavio Sztajnbok; Canada: David Cabral, Kristin Houghton, Johannes Roth, Heinrike Schmeling; France: Chantal Job-Deslandre, Christian Jorgensen, Isabelle Kone Paut; Germany: Kirsten Minden, Frank Weller-Heinemann; Italy: Valeria Gerloni, Francesco Zulian; Mexico: Ruben Burgos-Vargas, Carolina Duarte Salazar, Eunice Solis-Vallejo; Peru: Armando Calvo, José Chavez, Manuel Ferrandiz Zavaler; Poland: Anna Gruenpeter, Katarzyna Kobusinska; Russia: Alexey Sarychev, Elena Zholobova; UK: Athimalaipet Ramanan, Patricia Woo; USA: Steven Goodman, Abraham Gedalia, Yukiko Kimura, Karen Onel, Kenneth Schikler.

Contributors All authors edited and critically reviewed the manuscript drafts and approved of the final version submitted for publication. HIB performed a literature search and was involved in study design, collection and interpretation of data, and writing the manuscript. NR performed a literature search and was involved in figure preparation, study design, collection and interpretation of data, and writing the manuscript. ZZ was involved in collection and interpretation of data and writing the manuscript. CK was involved in analysis and interpretation of data and writing the manuscript. $\mathrm{OH}$ performed a literature search and was involved in data interpretation and writing the manuscript. AK was involved in study design, collection, analysis and interpretation of data, and writing the manuscript. PL was involved in figure preparation, analysis and interpretation of data, and writing the manuscript. RC, VK, RMX, IC, IN, NR-P, EA, VC, GH, VO-W, PQ, CAS, ES, AS, EB and MLGG were involved in collection and interpretation of data and writing the manuscript. CR was involved in collection and interpretation of data. DS and ES were involved in collection and interpretation of data and writing the manuscript. DL was involved in collection and interpretation of data and writing the manuscript. AM was involved in study design, collection and interpretation of data, and writing the manuscript. FDB was the principal investigator, performed a literature search and was involved in study design, collection, analysis and interpretation of data, and writing the manuscript.

Funding Funding for manuscript preparation was provided by F. Hoffmann-La Roche Ltd.

Competing interests HIB has in the past three years received honoraria and speaker bureau fees from AbbVie, Pfizer, AstraZeneca, Bristol-Myers Squibb, GlaxoSmithKline, Novartis, Roche and Janssen; the CCHMC, where she holds a full-time position, has received contributions to support the research activities of the PRCSG network (http://www.prcsg.org) from Roche, Abbott, AstraZeneca, Bristol-Myers Squibb, Janssen, Pfizer Inc. and Wyeth Pharmaceuticals Inc. NR has in the past three years received honoraria and speaker bureau fees from AbbVie, Alter, Medac, Novo Nordisk, Pfizer, Astellas, AstraZeneca, Bristol-Myers Squibb,

CD-Pharma, GlaxoSmithKline, Italfarmaco, MedImmune, Novartis, Roche, Sanofi Aventis and Vertex Pharmaceuticals; the GASLINI Hospital, where he works as a full-time employee, has received contributions to support the research activities of PRINTO (http://www.printo.it) from Abbott, AstraZeneca, Bristol-Myers Squibb, Janssen Biologics B.V., Eli Lilly and Company, 'Francesco Angelini', GlaxoSmithKline, Italfarmaco, Novartis, Pfizer Inc., Roche, Sanofi Aventis, Schwarz Biosciences GmbH, Xoma and Wyeth Pharmaceuticals Inc. ZZ declares no conflicts of interest. CK is an employee of Roche. OH was employed by F. Hoffmann La-Roche Ltd, the funding source, at the time the study was conducted. AK is an employee of Roche Products Ltd. PL was employed by Roche at the time the study was conducted. RC declares no conflicts of interest. VK declares no conflicts of interest. RMX has received funding for paid conferences and travel grants from Roche. ICP declares no conflicts of interest. IN has received consulting fees and travel grants from AbbVie, Bristol-Myers Squibb, Novartis, Pfizer and Roche. NR-P declares no conflicts of interest. EA has received research grants from Roche, Abbot, Pfizer, Bristol-Myers Squibb, Centocor and Novartis and has received honoraria as a speaker for Roche, Merck Sharp \& Dohme, Abbott, Bristol-Myers Squibb, Medac, Novartis and Pfizer. VC declares no conflicts of interest. GH has received grant/research support from AbbVie (Abbott) and Pfizer (Wyeth). VO-W declares no conflicts of interest. PQ has received research grants from AbbVie, Novartis and Pfizer and consultancy or speaker bureau fees from AbbVie, BMS, Chugai-Roche, Medlmmune, Pfizer, Novartis, Servier and Swedish Orphan Biovitrum. CAS declares no conflicts of interest. ES declares no conflicts of interest. AS declares no conflicts of interest. EB has received consulting fees and travel grants from AbbVie, Bristol-Myers Squibb, Novartis, Pfizer and Roche. MLGG declares no conflicts of interest. AM declares no conflicts of interest. CR declares no conflicts of interest. DS declares no conflicts of interest. ES declares no conflicts of interest. DL reports support from AstraZeneca, Centocor, Wyeth, Amgen, Abbot, Pfizer, Regeneron, Hoffmann-La Roche, Novartis, $U C B$, Horizon and Forest Research. AM has in the past three years received honoraria and speaker bureau fees from Novartis, GlaxoSmithKline, Boehringer Ingelheim, AstraZeneca, BMS, Sanofi, Medlmmune and Novo Nordisk; the GASLINI
Hospital, where he works as a full-time employee, has received contributions to support the research activities of PRINTO (http://www.printo.it) from Abbott, AstraZeneca, Bristol-Myers Squibb, Janssen Biologics B.V., Eli Lilly and Company, 'Francesco Angelini', GlaxoSmithKline, Italfarmaco, Novartis, Pfizer Inc., Roche, Sanofi Aventis, Schwarz Biosciences GmbH, Xoma and Wyeth Pharmaceuticals Inc. FDB has received an unrestricted grant and travel grants from Hoffmann-La Roche.

\section{Patient consent Obtained.}

Ethics approval The study was conducted in accordance with the Declaration of Helsinki and good clinical practice guidelines and with local requirements. Enrolment started 14 October 2009 and ended 31 January 2011.

Provenance and peer review Not commissioned; externally peer reviewed.

Open Access This is an Open Access article distributed in accordance with the Creative Commons Attribution Non Commercial (CC BY-NC 3.0) license, which permits others to distribute, remix, adapt, build upon this work non-commercially, and license their derivative works on different terms, provided the original work is properly cited and the use is non-commercial. See: http://creativecommons.org/ licenses/by-nc/3.0/

\section{REFERENCES}

1 Prakken B, Albani S, Martini A. Juvenile idiopathic arthritis. Lancet 2011;377:2138-49.

2 Ruperto N, Giannini EH, Pistorio A, et al. Is it time to move to active comparator trials in juvenile idiopathic arthritis? a review of current study designs. Arthritis Rheum 2010;62:3131-9.

3 Ravelli A, Martini A. Juvenile idiopathic arthritis. Lancet 2007:369:767-78.

4 Lovell DJ. Update on treatment of arthritis in children: new treatments, new goals. Bull NYU Hosp Jt Dis 2006;64:72-6.

5 Otten MH, Prince FH, Anink J, et al. Effectiveness and safety of a second and third biological agent after failing etanercept in juvenile idiopathic arthritis: results from the Dutch National ABC Register. Ann Rheum Dis 2013;72:721-7.

6 De Benedetti F, Robbioni P, Massa M, et al. Serum interleukin- 6 levels and joint involvement in polyarticular and pauciarticular juvenile chronic arthritis. Clin Exp Rheumatol 1992;10:493-8.

7 Mihara M, Kasutani K, Okazaki M, et al. Tocilizumab inhibits signal transduction mediated by both mIL-6R and sIL-6R, but not by the receptors of other members of IL-6 cytokine family. Int Immunopharmacol 2005;5:1731-40.

8 Nishimoto N, Kishimoto T. Humanized antihuman IL-6 receptor antibody, tocilizumab. Handb Exp Pharmacol 2008;181:151-60.

9 Navarro-Millan I, Singh JA, Curtis JR. Systematic review of tocilizumab for rheumatoid arthritis: a new biologic agent targeting the interleukin-6 receptor. Clin Ther 2012;34:788-802.e3.

10 De Benedetti F, Brunner HI, Ruperto N, et al. Randomized trial of tocilizumab in systemic juvenile idiopathic arthritis. N Engl J Med 2012;367:2385-95.

11 Ruperto N, Martini A. Networking in paediatrics: the example of the Paediatric Rheumatology International Trials Organisation (PRINTO). Arch Dis Child 2011;96:596-601.

12 Lovell DJ, Giannini EH, Reiff A, et al. Etanercept in children with polyarticular juvenile rheumatoid arthritis: Pediatric Rheumatology Collaborative Study Group. N Engl J Med 2000;342:763-9.

13 Brunner HI, Lovell DJ, Finck BK, et al. Preliminary definition of disease flare in juvenile rheumatoid arthritis. J Rheumatol 2002;29:1058-64.

14 Schulz KF, Altman DG, Moher D. CONSORT 2010 statement: updated guidelines for reporting parallel group randomised trials. BMJ 2010;340:c332.

15 Petty RE, Southwood TR, Manners P, et al. International League of Associations for Rheumatology classification of juvenile idiopathic arthritis: second revision, Edmonton, 2001. J Rheumatol 2004:31:390-2.

16 Giannini EH, Ruperto N, Ravelli A, et al. Preliminary definition of improvement in juvenile arthritis. Arthritis Rheum 1997;40:1202-9.

17 Wallace CA, Ruperto N, Giannini E, et al. Preliminary criteria for clinical remission for select categories of juvenile idiopathic arthritis. J Rheumatol 2004;31:2290-4

18 European Medicines Agency. ICH Topic E 2 A: Clinical safety data management: definitions and standards for expedited reporting: step 5. http://www.ema.europa. eu/docs/en_GB/document_library/Scientific_guideline/2009/09/WC500002749.pdf (accessed 13 Nov 2013).

19 Ruperto N, Lovell DJ, Quartier P, et al. Abatacept in children with juvenile idiopathic arthritis: a randomised, double-blind, placebo-controlled withdrawal trial. Lancet 2008:372:383-91

20 Schiff $\mathrm{MH}$, Kremer JM, Jahreis A, et al. Integrated safety in tocilizumab clinical trials. Arthritis Res Ther 2011;13:R141.

21 Daniels SR, Greer FR. Lipid screening and cardiovascular health in childhood. Pediatrics 2008;122:198-208.

22 Skinner AC, Steiner MJ, Chung AE, et al. Cholesterol curves to identify population norms by age and sex in healthy weight children. Clin Pediatr 2012;51:233-7. 